The rise in Danish unemployment reallocation or mismatch?

Albæk, Karsten; Hansen, Henrik

Publication date:

2004

Document version

Publisher's PDF, also known as Version of record

Citation for published version (APA):

Albæk, K., \& Hansen, H. (2004). The rise in Danish unemployment: reallocation or mismatch? Department of Economics, University of Copenhagen. 


\section{CAM}

\section{CAM}

Centre for Applied

Microeconometrics

Institute of Economics

University of Copenhagen

http://www.econ.ku.dk/CAMI

The Rise in Danish Unemployment:

Reallocation or Mismatch?

Karsten Albæk

Henrik Hansen

2004-13 


\title{
The Rise in Danish Unemployment: Reallocation or Mismatch?*
}

\author{
Karsten AlbæK ${ }^{\dagger}$ and Henrik Hansen ${ }^{\dagger}$ \\ ${ }^{\dagger}$ Institute of Economics and CAM, University of Copenhagen, Copenhagen, Denmark \\ (e-mail: karsten.albaek@econ.ku.dk) \\ ${ }^{\ddagger}$ Institute of Economics and DERG, University of Copenhagen,Copenhagen, Denmark \\ (e-mail: henrik.hansen@econ.ku.dk)
}

This is an electronic version of an Article published in

Oxford Bulletin of Economics and Statistics 66(4), 515-536

\begin{abstract}
The two main competing theories for the outward shift in the uv-curve are investigated: Increased separations from employment at a given employment level (reallocation) and decreased levels of hires, given unemployment and vacancies (mismatch). Shifts in the uv-curve and the hiring function are modelled by smooth transition functions, and the hypothesis of analogous shifts in the two curves is tested and accepted. This is interpreted as evidence in favor of the mismatch hypotheses.
\end{abstract}

\section{Introduction}

In attempts to identify the reasons for European unemployment, the relationship between vacant jobs and unemployment has an important role. As labour markets never clear, there are always vacant jobs and unemployed workers. However, if the features of the economy that generate vacancies and unemployment are unaltered over the business cycle, a stable negative relationship between vacancies and unemployment prevails: For any given rate of unemployment there is a corresponding vacancy rate. That is, there is a stable unemployment-vacancy curve (a uv-curve, also called a Beveridge curve).

One of the main reasons for the interest in analyzing the uv-curve and movements in the uv-plane is the potential for identifying the causes of changes in unemployment. An outward shift in the uv-curve indicates that unemployment has risen for reasons other than lack of demand for labour. Such an outward shift can come through two main channels: (1) A rise in the reallocation of workers, which is an increased level of separation of workers from employment, given the level of employment. Such increased reallocation implies a rise in both vacancies and unemployment. (2) Increased mismatch between

\footnotetext{
*We are grateful to Michael Burda, Herman van Dijk, Katarina Juselius, Jan van Ours, Adrian Pagan, Geet Ridder, Mark Watson, the editor and two anonymous referees for helpful comments. Thanks to Helle Juhler-Kristoffersen and Karina Ransby for research assistance.

JEL classification numbers: J41, J61
} 
the vacancies and the unemployed, which is a decreased level of hires, given the level of vacancies and unemployment. As vacancies are filled less rapidly, the unemployment rate will rise, given the level of vacancies.

Until now most attempts to distinguish between the reasons for outward shifts in the uv-curve have been based on how well different indices for either reallocation or mismatch have been able to explain such shifts. This paper demonstrates that it is possible to identify the channels of an outward shift in the uv-curve without indices for either reallocation or mismatch.

An equation where hires are related to vacancies and unemployment describes the matching of vacancies and the unemployed. Increased mismatch will result in a shift downwards in this hiring function. If increased mismatch is the source of the outward movement in the uv-curve, the shifts in the hiring function and the uv-curve should take place at the same time. In contrast, if increased reallocation is the source of the outward movement in the uv-curve, there is no shift in the hiring function. Increased reallocation implies that the volume of matching on the labour market increases (unemployment, vacancies and hires increase), but the matching process as such is unaltered.

Thus it is possible to distinguish between the two channels for an outward movement in the uv-curve by investigating whether the hiring function has moved inwards or not. Such an exercise demands a joint estimation of the uv-curve and the hiring function in order to test whether the movements in the two curves are analogous or not.

In the present paper the movements in the uv-curve and the hiring function are captured by estimating smooth transition functions in contrast to the common practice of describing the shifts by exogenous indices and linear trends. The smooth transition functions are deterministic functions in time, which are included in the equations to model shifts in parameters. This paper applies the functions introduced by Lin and Teräsvirta (1994). These functions are bounded between zero and one, whereby they have the appealing quality that they do not extend drifts in the equations indefinitely after the sample period, in contrast to the inclusion of linear trends. The analysis in Lin and Teräsvirta (1994) is confined to model parameter non-constancy in single equation regression models, while this paper extends the analysis by investigating whether two theoretical equations, the hiring function and the uv-curve, shift analogously.

The uv-curve is a long-run equilibrium equation. When an upturn sets in, increased labour demand results in more posted vacancies but as the matching process takes time, unemployment moves more slowly. Conversely, downturns begin with a decrease in the number of vacancies followed by a reduction in hires and increased unemployment. The existence of short-run movements around a long-run equilibrium equation makes it natural to describe the relationship between vacancies and unemployment by an errorcorrection model. In order to analyze the shift pattern of the uv-curve, estimation has to be conducted jointly with an estimation of the hiring function, which implies that movements in hires, vacancies and unemployment are to be analyzed. The natural way to analyze the adjustment towards long-run equilibrium in a system consisting of three variables is to conduct the analysis within the co-integrated vector autoregressive model (VAR-model), which is the modelling strategy pursued in this paper.

A review of the previous evidence on hiring functions and uv-curves is given in section II, including a discussion of the merits of the indices that have been applied to explain the outward shift in the uv-curve. Section III establishes the theoretical entities of interest 
for this study, the hiring function and the uv-curve, and discusses their properties and interrelations. In particular, we look at the possibility of identifying the causes of the shifts in the uv-curve. At the outset of section IV, we present the cointegrated VARmodel describing hires, unemployment and vacancies. The framework for this analysis is the systems approach of Johansen (1996). Two long-run linear combinations between the variables are identified, the hiring function and the uv-curve. These equations seem to have non-constant parameters, so we proceed to an analysis of a model with smooth shifts in the intercepts. We test whether the shifts in the two equations have the same time pattern and, as this is confirmed, we conclude that the shifts are due to increased mismatch. In section $\mathrm{V}$ we add some of the mismatch and reallocation indices discussed in section II to the model. The result is that the observed indices account for, at best, a small fraction of the increased mismatch in the Danish labour market. Finally, section VI gives concluding remarks.

\section{Previous evidence on uv-curves and hiring functions}

The outward shift in the uv-curve is a general phenomenon, as noted for example in the multi-country study by Jackman, Pissarides and Savouri (1990). ${ }^{1}$ However, shifts in both uv-curves and hiring functions have also been observed in many studies for single countries. $^{2}$

For the US, Abraham (1987) contains a detailed discussion of various measurement issues in relation to the US Help-Wanted Index and models the outward drift in the uvcurve by a positive linear trend. Blanchard and Diamond (1990) estimate various hiring functions that typically contain a significant negative linear trend. Their paper does not include an explicit estimating equation for the uv-curve, but through a structural VAR analysis they find support for an outward shift in the curve due to reallocation (Blanchard and Diamond, 1990, p. 47). Abraham and Katz (1986) analyze how an index of changes in employment shares across American industries affects unemployment and vacancies. If increased reallocation, as measured by this index of sectoral shifts, causes increased unemployment, the index should be able to explain a rise in both unemployment and vacancies. However, while the index has a positive coefficient in an equation explaining unemployment, it has a negative coefficient in an equation explaining vacancies. This is what one would expect for a variable reflecting aggregate demand, and thus the authors argue that sectoral shifts have been caused by changes in aggregate demand and did not have an independent role in explaining the development of unemployment in the sample period, which is in contrast to the hypothesis by Lilien (1982). ${ }^{3}$

Turning to Europe, Franz (1987) included time trends to describe the outward shift in the German uv-curve. Trends are also applied by Burda and Wyplosz (1994) in the

\footnotetext{
${ }^{1}$ As their focus was on the impact of labour market policy in different countries, they removed the common outward shift from their data.

${ }^{2}$ The empirical literature on matching functions is surveyed by Pissarides and Petrongolo (2001). They also discuss the recent extention of the time-series literature to the estimation of matching on regional data.

${ }^{3}$ Davis and Haltiwanger (1999), section 9.3, contains an overview of the empirical evidence on the role of allocative shocks in the US. This includes recent attempts to use information about employment adjustment at the plant level and the analysis of the impact of changes in energy prices. Several of the contributions apply the structural VAR methodology, where the idea that aggregate shocks and allocative shocks generate different covariance properties for key variables is used to identify the models.
} 
estimation of matching functions for France, Germany, Spain and the UK.

For the UK, Layard, Nickell and Jackman (1991, p. 262) find a hiring function with a negative linear trend, and a uv-curve with a positive linear trend (p. 268). Pissarides (1986) estimates a hiring function including a third order polynomial in time, where the two first coefficients are negative and the last positive. Attempts have been made to explain the shift in the uv-curve for the UK by the inclusion of variables such as the replacement ratio of unemployment benefits, an index for the dispersion between vacancies and unemployed across different regions, and, most notably, according to the claims of the authors, the share of long-term unemployed. This variable comes out with a positive coefficient in Budd et al. (1988), in Jackman et al. (1989) and in Layard et al. (1991), but the equations still contain positive trends.

Although the present authors are sympathetic to the idea of including extraneous information in order to account for the shift in the uv-curve, the information contained in the two main contending indices is not without problems. With respect to Lilien's measure of sectoral shifts of employment across industries, this index captures only part of the reallocation of employment opportunities in the economy. The bulk of reallocation of jobs takes place among establishments within industries, see Davis and Haltiwanger (1992). For Denmark, data on both job and worker reallocation are available, see Albæk and Sørensen (1998), but not for the period where by far most of the rise in unemployment took place (the first year of the linked employer-employee data sets is 1980).

With respect to the index of long-term unemployment, this seems to be correlated with the outward shift in the uv-curve, which has taken place during a period of rising unemployment. When unemployment goes up, it is not unnatural that the share of workers with say, unemployment spell lengths of one year or more, increases. This is the outcome of a proportional downward shift in the hazard rates across different spell-lengths of unemployment; a constant share of long-term unemployed can only be obtained when hazard rates across spell-lengths are pivoted in a less steep direction when unemployment goes up. And even if long-term unemployment plays a role in the shift of the uv-curve, the variable, as such, is unfortunately uninformative with respect to whether the problems of re-employment stems from the supply or the demand side, which is the relevant question for policy analysis.

A final important topic is the distinction between hires from unemployment and hires from employment or from outside the labour force, and the extent to which there is a different reaction pattern of these types of flows on changes in vacancies and unemployment. This has been investigated in a series of recent papers, Burgess (1993), Broersma and Van Ours (1999), Mumford and Smith (1999), and Anderson and Burgess (2000). These papers do not consider uv-curves, and an extension of the analysis in the present paper would be to apply the methodology to the case where separate information for these two types of transitions was present, which is not the case for the data analyzed in the following.

\section{A model of labour market flows}

In this section we discuss a model for the flows into and out of unemployment. The aim of the model is to describe equilibrium relations between hires, unemployment and vacancies. Special emphasis in the derivations is placed on the sources of shifts in the 
uv-curve and the hiring function. The model is specified to comply with the data in the empirical analysis: Hires include transitions from both unemployment and employment, and vacancies are oriented towards unemployed workers. ${ }^{4}$

The stock of workers (the labour force) in each period is denoted by $N_{t}$. The workers are either employed or unemployed such that $N_{t}=E_{t}+U_{t}$, where $E_{t}$ is the stock of employed workers and $U_{t}$ is the stock of unemployed workers.

The flows into and out of employment are given by the number of hires $\left(H_{t}\right)$ and separations $\left(S_{t}\right)$, and the change in employment is given as

$$
\Delta e_{t}=h_{t}-s_{t}\left(1-u_{t}\right) \text {, }
$$

where $h_{t}$ is the ratio of new hires to the labour force $\left(H_{t} / N_{t}\right), s_{t}$ is the ratio of separations to the number of employed workers $\left(S_{t} / E_{t}\right)$, and $1-u_{t}=e_{t}=E_{t} / N_{t}$ is the employment rate.

The forces governing the flow rates on the right hand side of (1) are described by two behavioral equations. For hires, we assume that the matching of vacant jobs and unemployed workers can be described by a hiring function. This function maps the stock of vacancies and the stock of unemployed into the flow of workers entering employment from unemployment. The hiring function is approximated by a Cobb-Douglas function with constant returns to scale. The data for vacancies are the number of vacant positions registered at the employment offices. These vacancies are posted by firms who wish to hire unemployed workers. The outcome of the match between unemployed workers and vacancies registered at the unemployment offices is an unemployment-employment transition. However, the hiring data includes all transitions into employment, hence employmentemployment transitions are included. Denoting the fraction of hires from unemployment as $F_{t}$, unemployment-employment transitions become $F_{t} h_{t}$. Consequently, we get the following hiring function, describing the matching between vacancies and unemployed workers

$$
\ln h_{t}=-m_{t}-f_{t}+\phi \ln u_{t}+(1-\phi) \ln v_{t}+\varepsilon_{1 t}, \quad 0<\phi<1,
$$

where $v_{t}=V_{t} / N_{t}$ is the vacancy rate (the stock of vacancies relative to the labour force), $f_{t}=\ln F_{t}, \phi$ is the weight of the unemployed in the matching process, and $\varepsilon_{1 t}$ is an error term. The term $m_{t}$ measures the effectiveness of the matching process. Higher levels of $m_{t}$ signify increased mismatch between unemployed workers and vacant jobs. ${ }^{5}$ A corresponding movement in the hiring function occurs if the share of hires from unemployment increases ( $f_{t}$ goes up) ${ }^{6}$

\footnotetext{
${ }^{4}$ Vacancies are registered at the government labour exchange offices. When a firm notifies the labour exchange office of a vacancy, the latter is required to identify suitable unemployed workers and send them for interview.

${ }^{5}$ Although this terminology for an entity like $m_{t}$ is a common one in the literature, some authors, for example Layard et al. (1991), do not include effects from low search intensity among long-term unemployed and increased choosiness from employers in this concept.

${ }^{6}$ As Pissarides and Petrongolo (2001) note, the match between the flow variable on the left-hand side and the stock-variables on the right hand side could be better in many empirical studies. They have an informative discussion of some of the possible biases that can arise when estimating an equation like (2) including congestion externalities if the search intensity of employed workers varies across labour market states.
} 
As our hiring data contains employment-employment transitions, we turn to separations out of employment. These consist of two flows: (1) Employment to employment transitions $\left(Q_{t}\right)$ and (2) employment to unemployment transitions $\left(L_{t}\right)$, which we denote as lay-offs in the following. Hence the separation rate is $s_{t}=q_{t}+l_{t}$ where $q_{t}=Q_{t} / E_{t}$ and $l_{t}=L_{t} / E_{t}$.

The employment-unemployment transition rate $l_{t}$ is assumed to follow the relation

$$
\ln l_{t}=r_{t}-\theta \ln \left(v_{t} / u_{t}\right)+\varepsilon_{2 t}, \quad \theta>0 .
$$

The first term on the right hand side, $r_{t}$, measures structural changes in the economy causing changes in the rate of layoffs at a given level of economic activity. An increase in $r_{t}$ could be due to increases in the change of employment between different sectors in the economy as in the index by Lilien (1982), or an increased level of job reallocation within sectors. The second term, $v_{t} / u_{t}$, is labour market tightness. This term measures the relationship between the level of economic activity and the rate of layoffs, where increased tightness in the labour market implies fewer layoffs. The last term, $\varepsilon_{2 t}$, is an error term.

As the share of hires originating from employment is $\left(1-F_{t}\right)$, the relation between the employment-employment transition rate $q_{t}$ and the hiring rate is given by

$$
\ln q_{t}=\ln h_{t}+\ln \left(1-F_{t}\right)-\ln \left(1-u_{t}\right) .
$$

Eliminating $s_{t}$ in the flow equation (1) and inserting (4) yields

$$
\Delta e_{t}=F_{t} h_{t}-\left(1-u_{t}\right) l_{t}
$$

The first term on the right hand side is unemployment-employment transitions while the second term is employment-unemployment transitions. In contrast to (1), the terms on the right hand side of (5) does not include job to job transitions.

Steady state is characterized by a constant employment rate, $\Delta e_{t}=0$. Applying this condition to (5) and inserting the expression for $h_{t}$ and $l_{t}$ from (2) and (3) yields

$$
(\phi-\theta) \ln u_{t}-\ln \left(1-u_{t}\right)=r_{t}+m_{t}-(1-\phi-\theta) \ln v_{t}+\varepsilon_{1 t}-\varepsilon_{2 t} .
$$

Here the uv-curve is implicitly defined as a relation between vacancies and unemployment. Using the approximation $\ln \left(1-u_{t}\right) \simeq \ln (1-\bar{u})+\frac{\bar{u}}{1-\bar{u}} \ln \bar{u}-\frac{\bar{u}}{1-\bar{u}} \ln u_{t}$ changes the coefficient of $\ln u_{t}$ on the left hand side of (6) from $\phi-\theta$ to $\gamma=\phi-\theta+\bar{u} /(1-\bar{u})$, where $\bar{u}$ is the point of expansion. The parameter $\gamma$ is likely to be positive, which will be assumed in the following. With this reformulation, we get a log-linear formulation of the uv-curve $^{7}$

$$
\ln u_{t}=\left(r_{t}+m_{t}+\mu\right) / \gamma-\kappa \ln v_{t}+\varepsilon_{3 t}, \quad \kappa=(1-\phi-\theta) / \gamma,
$$

where $\mu=\ln (1-\bar{u})+\frac{\bar{u}}{1-\bar{u}} \ln \bar{u}$ and the error term is $\varepsilon_{3 t}=\left(\varepsilon_{1 t}-\varepsilon_{2 t}\right) / \gamma$.

\footnotetext{
${ }^{7}$ Alternatively we could specify hirings, vacancies and unemployment as fractions of employment instead of the labour force. In this case the log linear uv-curve is exact in our model of hirings and separations. However, we have chosen to keep the standard uv-curve formulation, using unemployment and vacancies as fractions of the labour force.
} 
From the first term on the right hand side in (7) it follows that increased reallocation (larger $r_{t}$ ) will shift the uv-curve outwards. The same is the case with increased mismatch in the economy (larger $m_{t}$ ).

It is now possible to trace how movements in unemployment, vacancies and hires opens up the potential for identifying the causes of changes in unemployment. In the present model comprising of a hiring function in (2) and a uv-curve in (7), identification of changes in the different factors affecting the transition processes can be obtained from the fact that they have a differential impact on the levels of the two curves.

Consider first increased mismatch on the labour market given as an increase in $m_{t}$. From (2) this will result in a decreased level of hires given unemployment and vacancies; a downward shift in the hiring function. From (7) increased mismatch will result in an increased level of unemployment given vacancies; an outward shift in the uv-curve. So a downward shift in the hiring function and a parallel outward shift in the uv-curve is an indication of increased mismatch in the labour market.

Increased structural change in the economy given the level of economic activity can be described as a change in $r_{t}$. As $r_{t}$ is not included in equation (2), the hiring function is unchanged, while it follows from (7) that the unemployment rate increases given the level of vacancies; an outward shift in the uv-curve. Hence, the presence of a constant hiring function and an outward shift in the uv-curve is an indication of increased structural change in the labour market.

Consider finally the role of the share of hires from unemployment, $f_{t}=\ln F_{t}$. Hires from unemployment is $F_{t} h_{t}$, where $h_{t}$ is observed in the data and $F_{t}$ is not observed. A lower level of employment-employment transitions, given the matching process of the unemployed and vacancies, will show up as a decrease in $h_{t}$ and a corresponding increase in $f_{t}$. In this case a downward shift in the hiring function can be attributed to a decreased level of on the job search. However, unemployment in (7) is unaffected as $f_{t}$ does not enter the uv-curve. Hence, a downward shift in the hiring function and a constant uv-curve is an indication of a relatively smaller weight of search from employment relative to search from unemployment.

Stated slightly differently, factors affecting the flow from unemployment into employment will lead to changes in both the hiring function and the uv-curve. Factors affecting the flow out of employment to unemployment only give rise to changes in the uv-curve, leaving the hiring function unaltered. Factors affecting the flow from employment to employment, given the level of unemployment, vacancies and the flow from unemployment to employment, will affect the hiring function but not the uv-curve. These properties of the model will be pursued in an analysis of the changes over time in the two equations (2) and (7).

\section{A minimalist model of hires, unemployment, and vacancies}

The line of thought behind the hiring function in equation (2) is that members of the stock of unemployed and members of the stock of vacancies meet and make a match into employment. Correspondingly the empirical analysis is based on stock data for vacancies and unemployment.

Vacancies are the number of unfilled orders at the labour exchange at the last day in each quarter. It is a standard practice in the European literature to apply vacancies 
registered at the labour exchange as a proxy for the true number of vacancies, see for example the study on regional British Beveridge curves in Wall and Zoega (2002). ${ }^{8}$ In the Danish case the available evidence shows a high correlation between this measure and a help-wanted index, which is the main competing index used in the empirical literature on vacancies. ${ }^{9}$ Unemployment is a similar quarterly stock measure, and data for both vacancies and unemployment has been published by Statistics Denmark. As opposed to most studies on British data, which approximate hires with either the outflow from unemployment, as in Layard et al. (1991), or the outflow of vacancies notified to the labour exchange, as in Robson (2001), we are able to apply a series that directly measures the number of new hires. Hires is a constructed series based on the rate of gross quarterly inflows of workers to firms that are members of the Danish Confederation of Employers multiplied by the official quarterly employment series. The Danish labour market is highly unionized, and during the sample period, Statistics Denmark considered employment in firms that were members of the Confederation of Employers as being representative of the private sector to such a degree that the only official wage statistics published for the private sector came from this source. Public sector hiring is close to acyclical according to the available evidence, which implies that the measurement error in correlations with business cycle indicators, due to the omission of public sector hiring, is negligible. ${ }^{10}$

Quarterly observations of the three series for the period 1974:3 - 1988:4 are shown in Figure 1, in which the vacancy rate is multiplied by 100 to match the range of hires and unemployment. ${ }^{11}$ The movements in the uv-plane are shown in Figure 2, where we have removed the seasonal components by using centered, four quarter moving averages of the unemployment and vacancy rates.

The system comprising hires, unemployment, and vacancies is a minimal model for the flows in the labour market. Such a system enables us to investigate the interrelationships between the variables $\ln h_{t}, \ln u_{t}$, and $\ln v_{t}$ and it opens the possibility of identifying a hiring function and a uv-curve. The differences in the timing of the changes in the vacancy and the unemployment rates requires an estimation strategy in which the difference between the short run and the long run is modelled explicitly. As the cointegrated VAR-model contains a description of the long-run relations and the short-run dynamics, this framework is particularly suited to the present analysis.

We use a partial VAR-model in which the vacancy rate is assumed to be weakly exogenous with respect to the long run parameters. This assumption is tested and accepted

\footnotetext{
${ }^{8} \mathrm{~A}$ good discussion of the various issues in relation to the registration of vacancies at the labour exchange is contained on the homepage of NOMIS.

${ }^{9}$ The Pearson correlation coefficent between the two series for the period 1991-1996 is 0.86, calculated on the basis of the data for Figure 1 in Slø k (1997). The two first years in the series from this paper are omitted because of a price war during 1988-1990 on the market for job advertising (the impact of changes in the competition on the newspaper market on help-wanted indices is well known from the American literature on vacancies).

${ }^{10}$ According to Bingley et al. (1999), p. 24, the Spearman rank correlations between public sector hiring on an annual frequency and the change in GDP was -0.15 during 1980-1995, while the corresponding figure for the private sector was 0.60 (the marginal p-values for the two figures are 0.46 and 0.02 ).

${ }^{11} \mathrm{~A}$ change in the registration system at the labour exchange offices from 1989 and onwards resulted in a break in the vacancy series. Furthermore, the hiring series was discontinued in 1993. For the present purpose, we consequently stop the analysis in 1988. The American hiring series was discontinued in 1982, which is another example of the constraints from data availability in the empirical literature on matching.
} 


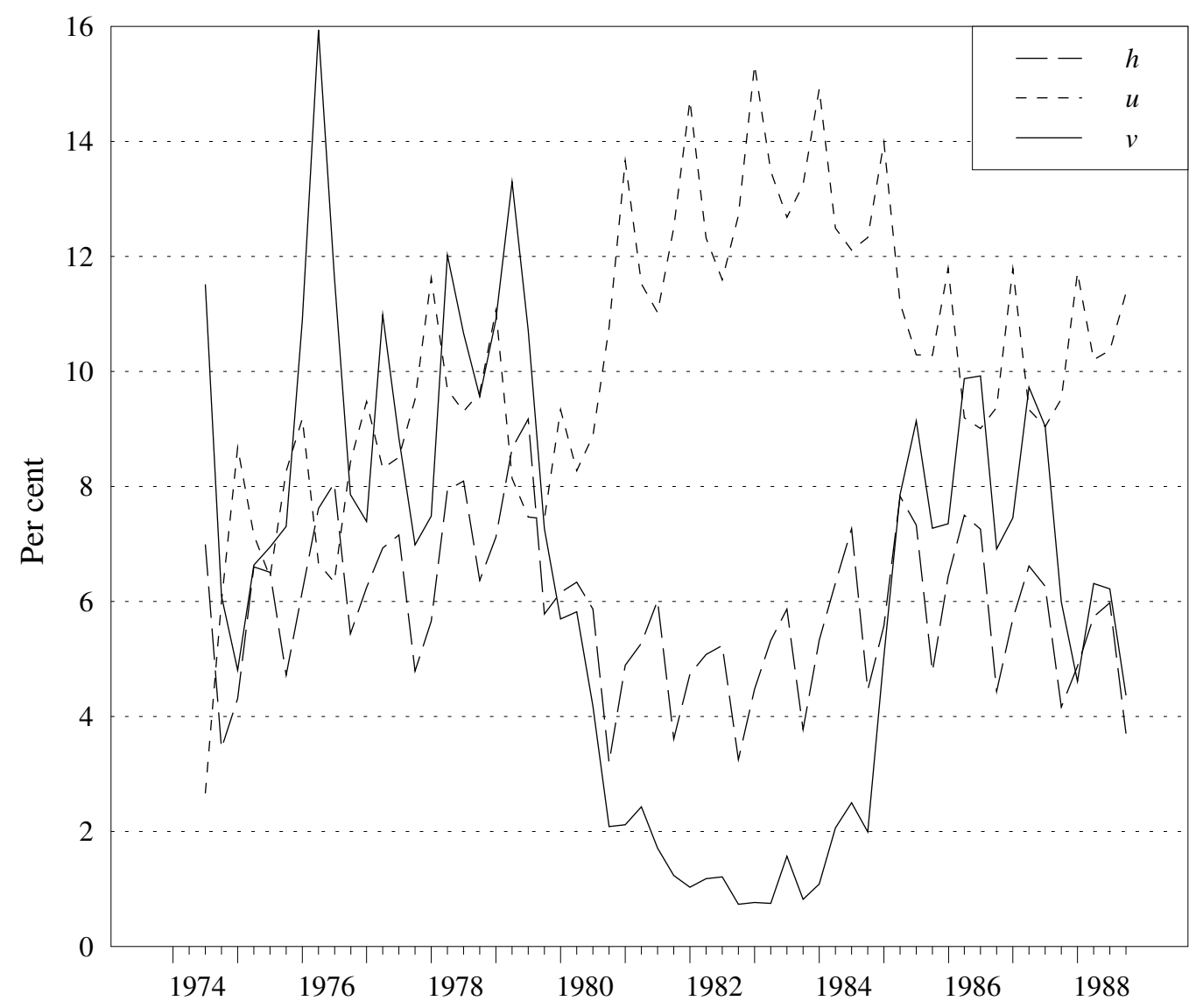

Figure 1. Hirings, unemployment and vacancies in Denmark 1974-1988 (The vacancy rate is multiplied by 100)

below, and the model is thus formulated in an error correction form as

$$
\Delta y_{t}=\Gamma_{0} \Delta \ln v_{t}+\Gamma_{1} \Delta x_{t-1}+\alpha \beta^{\prime} x_{t-1}+\alpha \delta+\Phi D_{t}+\eta_{t},
$$

where $y_{t}^{\prime}=\left(\ln h_{t}, \ln u_{t}\right), x_{t}^{\prime}=\left(\ln h_{t}, \ln u_{t}, \ln v_{t}\right)$, and $D_{t}$ is a vector of centered seasonal dummies. $\beta$ is a matrix of cointegration vectors of dimension $3 \times r$ where $r$ is the number of cointegration vectors, and $\alpha$ is a $2 \times r$ matrix of feed back coefficients. $\delta$ is an $r$-dimensional vector of intercepts in the cointegration space, and $\Gamma_{0}$ measures the contemporaneous correlations between $\Delta \ln v_{t}$ and $\Delta \ln h_{t}, \Delta \ln u_{t}$, where $\Delta$ is the difference operator. The error term $\eta_{t}$ is assumed to be Gaussian with mean zero and variance $\Omega$.

The number of cointegration vectors is determined by comparing the rank test statistics in Table 1 with the percentiles of the asymptotic distributions given in Harboe et al. (1998). For the hiring function and the uv-curve to be equilibrium linear combinations of the variables, this requires stationarity of both of them. Thus, we expect to find two cointegration vectors. As seen from Table 1 there is quite strong empirical support for a choice of two cointegration vectors. It follows from Granger's representation theorem that there is one common stochastic trend in the system, see Johansen (1996).

Stationarity of any one of the three series can be investigated within the model by testing whether the series by itself is one of the two cointegration vectors. Likelihood 


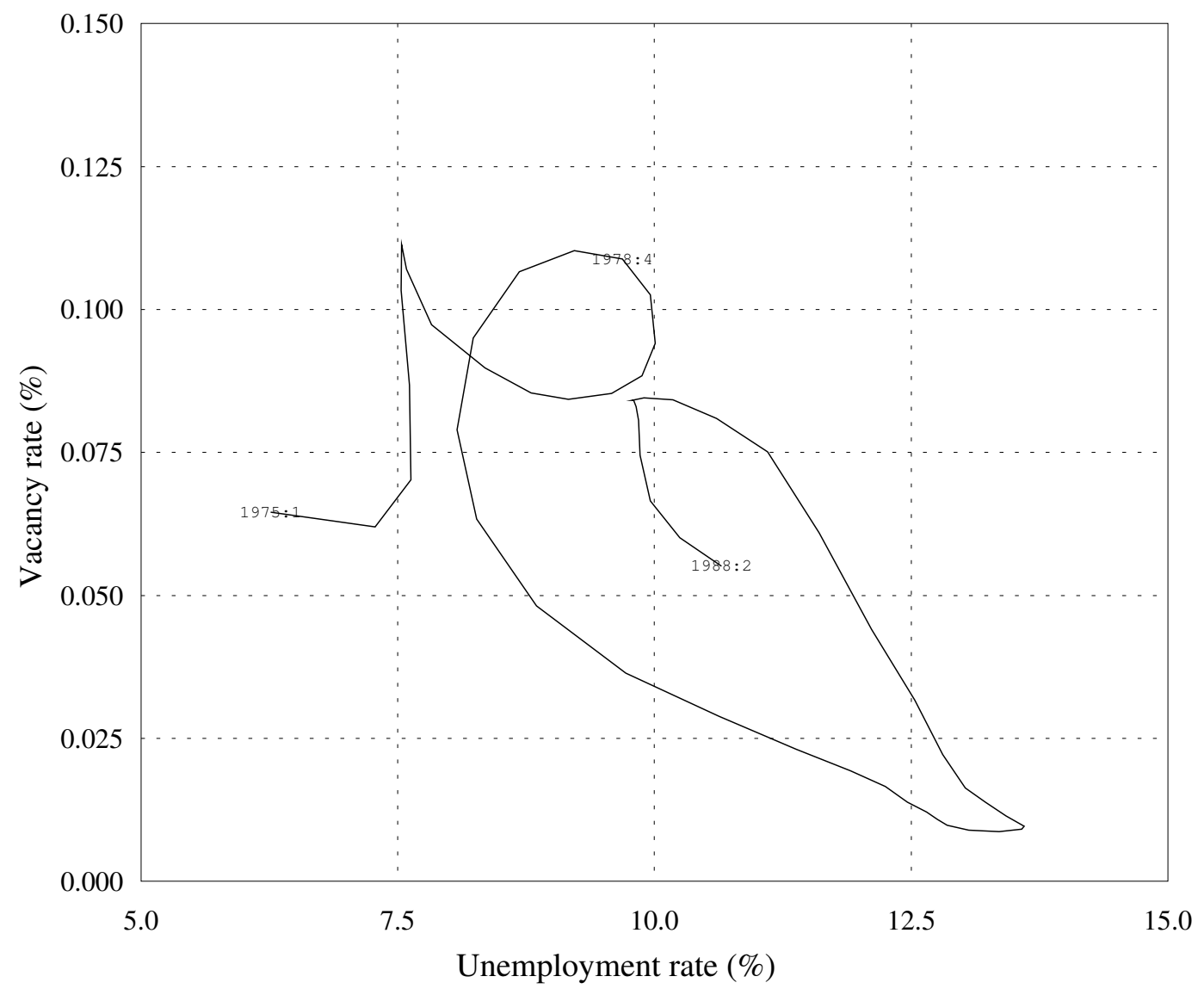

Figure 2. Unemployment and vacancies. (4-quarter centered moving averages)

ratio test statistics for stationarity of the individual series are shown in the lower part of Table 1 along with tests of weak exogeneity. ${ }^{12}$ The test statistics for stationarity are all in the extreme upper tail of the asymptotic distribution, implying that the three series should be modelled as I(1) series in this system. The tests for weak exogeneity lead to rejection for hires and unemployment, but not for vacancies. The implication is that the vacancy rate is the driving force of the VAR-model, such that the two other variables, the unemployment rate and the hiring rate, adjust to movements in vacancies. This is in agreement with theoretical work in the area aimed at rationalizing the counter-clockwise cyclical movements in the uv-plane, see Pissarides (1985).

The estimated coefficients of the long-run hiring function and the uv-curve are shown in Table 2. The parameters in the hiring function are not far from estimates in many other studies, the coefficient on unemployment is typically in the range 0.5-0.7, see Pissarides and Petrongolo (2001). However, the main issue in the present analysis is whether the parameters are constant over time.

Tests of constancy of the parameters are presented in the lower part of Table 2. The first test is a LM-type test of constancy of all parameters in the cointegration relations, see Hansen and Johansen (1999). The second test is specified to test for changes in the

\footnotetext{
${ }^{12}$ Weak exogeneity is a test of the hypotheses that the cointegration vectors do not have a significant impact on the changes in the individual series.
} 
TABLE 1

Tests for cointegration rank, stationarity, and weak exogeneity.

\begin{tabular}{lll}
\hline Rank & Test statistic & $5 \%$ Critical value \\
\hline 0 & 56.4 & 25.5 \\
1 & 14.0 & 12.3 \\
& Stationarity, $\chi^{2}(1)$ & Exogeneity, $\chi^{2}(2)$ \\
$\ln h_{t}$ & 6.27 & 16.44 \\
$\ln u_{t}$ & 11.82 & 42.32 \\
$\ln v_{t}$ & 13.26 & 2.71 \\
\hline Notes: The critical values for the rank tests are from Harboe et al. (1998, Table 3). The test for weak \\
exogeneity of vacancies is a LM type test.
\end{tabular}

TABLE 2

Regression results: The long-run hiring function and $u v$-curve

\begin{tabular}{lcccc}
\hline & $\begin{array}{c}\text { Hiring function } \\
\left(\ln h_{t}\right)\end{array}$ & $\begin{array}{c}u v \text {-curve } \\
\left(\ln u_{t}\right)\end{array}$ & $\begin{array}{c}\text { Hiring function } \\
\left(\ln h_{t}\right)\end{array}$ & $\begin{array}{c}\text { uv-curve } \\
\left(\ln u_{t}\right)\end{array}$ \\
\hline $\ln u_{t}$ & $0.740(0.033)$ & & $0.657(0.048)$ & \\
$\ln v_{t}$ & $0.260(0.033)$ & $-0.213(0.036)$ & $0.343(0.048)$ & $-0.265(0.048)$ \\
Constant & $0.826(0.179)$ & $-3.764(0.272)$ & $1.708(0.188)$ & $-4.647(0.318)$ \\
$\hat{F}(t)$ & & & $-0.599(0.144)$ & $0.486(0.109)$ \\
Parameter constancy & & & & \\
All parameters & 2.18 & & 1.19 & \\
Intercept & 32.7 & & & \\
\hline
\end{tabular}

Notes: Conditional standard errors in parentheses. The test for constancy of all the parameters in the cointegration space is the mean $Q_{T}$ test from Hansen and Johansen (1999). The $1 \%$ critcal value is 1.36 . The test for constancy of the intercept is the LM type test from Lin and Teräsvirta (1994). A third order polynomial in time is used in the test. The $1 \%$ critical value is 16.8 . The estimated transition function is $\hat{F}(t)=\left(1+\exp \left\{-0.643\left(\tau^{3}-7.684 \tau^{2}+17.032 \tau-9.087\right\}\right)^{-1}\right.$.

intercepts over time in the cointegration relations, see Lin and Teräsvirta (1994). Both test statistics lead to the rejection of a hypothesis of constant parameters.

There are various ways of resolving the problem of non-constant parameters in the long-run equations. One approach is to include more information in the system to account for the changes in the equations. This approach is the most informative with respect to the processes in the labour market, but, as discussed in section II, it has proved to be difficult to find the relevant information in aggregate time series. Another approach is to include deterministic changes over time in some of the parameters, which is the one we follow. The model is thus extended to allow for deterministic changes in the intercepts.

Our approach is to estimate a continuous deterministic change in the scale parameter in the hiring function and in the location of the uv-curve, keeping the elasticities constant over time. Accordingly, a new statistical model for the changes in the hiring rate and the unemployment rate is given by

$$
\Delta y_{t}=\Gamma_{0} \Delta \ln v_{t}+\Gamma_{1} \Delta x_{t-1}+\alpha \delta+\alpha \beta^{\prime} x_{t-1}+\alpha \psi^{\prime}\left[\begin{array}{c}
F_{h}(t) \\
F_{u}(t)
\end{array}\right]+\Phi D_{t}+\eta_{t},
$$

where $\psi$ is a $2 \times 2$ matrix with zeros off the diagonal and unknown parameters on 
the diagonal. When the identifying restrictions, analogous to the previous section, are imposed on the long-run relations in (9), $\beta^{\prime} x_{t-1}$ contains a homogeneous hiring function in the first row and a uv-curve in the second row.

The $F_{h}(t)$ function thus enters in the equation for the hiring function, and the $F_{u}(t)$ function enters in the equation for the uv-curve. The $F_{i}(t)$ functions are given by

$$
F_{i}(t)=\left(1+\exp \left\{-\gamma_{i 3}\left(\tau^{3}+\gamma_{i 2} \tau^{2}+\gamma_{i 1} \tau+\gamma_{i 0}\right)\right\}\right)^{-1}, \quad i=h, u, \quad \tau=0.1,0.2, \ldots
$$

This logistic function is bounded between zero and one, hence the drift in the intercept will not continue indefinitely after the sample period. The function describes the transition from one level of the intercept to another. Furthermore, it can potentially describe the timing of drift during the sample period, as a transition with this type of function is not necessarily monotonic. ${ }^{13}$

The shapes of the two functions, $F_{h}(t)$ and $F_{u}(t)$, provide important information about the changes in the equilibrium level of unemployment. As noted in Section III, changes in the matching process are captured by the mismatch process, $m_{t}$, which is included in both the intercept of the hiring function and the intercept of the uv-curve, that is, in both $F_{h}(t)$ and $F_{u}(t)$. In contrast, structural changes are captured by the reallocation process, $r_{t}$, which is only included in the intercept of the uv-curve, that is, in $F_{u}(t)$. Therefore, if the two time functions $F_{h}(t)$ and $F_{u}(t)$ are equal, shifts in the uv-curve can be attributed to changes in the matching process. ${ }^{14}$

A likelihood ratio test of the hypothesis $F_{h}(t)=F_{u}(t)$, which is asymptotically distributed as $\chi^{2}(4)$, results in a test statistic of 5.93, whereby the hypothesis of equal time patterns in the uv-curve and the hiring function is accepted at conventional levels of significance. This means that the model can be simplified to include only one common deterministic function. The estimated parameters of this model are reported in Table 2.

The Hansen and Johansen test for parameter constancy is much lower for the smooth transition model and below the $1 \%$ critical value. Thus, the changing intercepts do account for most (if not all) of the instability in the long run parameters.

The inclusion of the drift function causes some changes in the elasticities of the hiring function and the uv-curve compared to the results without the drift function. The elasticity with respect to unemployment in the hiring function is now smaller and the elasticity with respect to vacancies is consequently larger. The elasticity of the uv-curve is also numerically larger.

The shift function $\widehat{F}(t)$ goes from the lower boundary of zero to the upper boundary of one during the sample period. This implies that the coefficient of this function in the estimate of the uv-curve in Table 2 is an estimate of the proportional shift of the uvcurve during the sample period, and the point estimate of 0.486 evaluates the increase in unemployment to be about $50 \%$ at any given level of vacancies. However, according to the estimated transition function, the development towards an aggravated relationship between unemployment and vacancies has not been monotonic over the sample period.

\footnotetext{
${ }^{13}$ The reason for indexing the function with $\tau$, where the step-length is one tenth of the index $t$ for the quarterly observations, is solely for the sake of presentation, this indexing yields parameter values not too far from one.

${ }^{14}$ We recognize the possibility that the changes in $m_{t}$ and $r_{t}$ could have been identical in the sample period, and that in this case it is not possible to identify the cause of the drift in the uv-curve. We assume that the probability of this event is small enough to be neglected.
} 
The outward shift in the uv-curve corresponds to an analogous shift inwards in the hiring function, and the magnitude of this shift can be assessed from the point estimate to $\widehat{F}(t)$ in the estimate of the hiring function in Table 2 . This shows that the proportional shift downwards in the hiring function has been about $60 \%$ during the sample period. This is the reduction in hires for a given level of vacancies and a given level of unemployment. As the outward shift in the uv-curve indicates that unemployment has gone up by about $50 \%$ at any given level of vacancies, this shift represents a partial increase in hires by about $32 \%(0.486 \times 0.657)$. That is, the inward shift of the hiring function results in a net reduction in hires of about $28 \%(60-32)$ at any given level of vacancies.

\section{Adding observable mismatch and reallocation measures to the minimalist model}

In this section we assess whether some of the observable indices of mismatch and reallocation discussed in section II are capable of explaining the estimated changes in the hiring function and the uv-curve. Specifically, we look at two measures of mismatch, one measure of reallocation and the replacement ratio.

Ideally both measures of mismatch should be directly related to the hiring function, i.e., they should incorporate both unemployment and vacancies. However, it is only possible to calculate consistent measures for the regional distribution of unemployment and vacancies. Across occupations we only have the distribution of unemployment. In our computation of mismatch measures we follow Jackman, Layard and Savouri (1990) although we do not use measures that impose restrictions on the parameters in the hiring function.

Following Jackman, Layard and Savouri (1990), regional mismatch can be defined as

$$
m_{t}^{r}=\frac{1}{2} \operatorname{Var}\left(\frac{v_{i t}}{v_{t}}-\frac{u_{i t}}{u_{t}}\right)
$$

where $v_{i t}$ and $u_{i t}$ are the regional vacancy and unemployment rates at time $t$, while $v_{t}$ and $u_{t}$ are the national averages. In the empirical analysis to follow, vacancies and unemployment are measured across 14 regions corresponding to the Danish counties, the largest regional unit in Denmark.

Occupational mismatch is only measured for unemployment, hence, the index is given by

$$
m_{t}^{o}=\frac{1}{2} \operatorname{Var}\left(\frac{u_{i t}}{u_{t}}\right)
$$

where $u_{i t}$ is the unemployment rate in the 11 different occupational groupings, using unemployment insurance funds as the prime group indicator.

The reallocation indicator is calculated as Lilien's turbulence index using 8 industrial sectors. Hence, the turbulence index is given by

$$
r_{t}=\left(\sum_{i} \frac{E_{i t}}{E_{t}}\left(\Delta \log E_{i t}-\Delta \log E_{t}\right)^{2}\right)^{\frac{1}{2}},
$$

where $E_{i t}$ is employment in sector $i$ at time $t$ and $E_{t}$ is total employment that year. ${ }^{15}$

\footnotetext{
${ }^{15}$ The correlation between the Lilien index and an index computed as in Jackman, Layard and Savouri (1990) is 0.98 . Therefore we only report results for one industry turbulence index.
} 
TABLE 3

Mismatch and turbulence measures 1974-1988

\begin{tabular}{ccccc}
\hline Year & $\begin{array}{c}\text { Unemployment,vacancies } \\
\text { region }\end{array}$ & $\begin{array}{c}\text { Unemployment } \\
\text { Occupation }\end{array}$ & $\begin{array}{c}\text { Lilien Index } \\
\text { (x 100) }\end{array}$ & $\begin{array}{c}\text { Replacement ratio } \\
\text { (Annual average) }\end{array}$ \\
\hline 1974 & 0.390 & 0.178 & 1.571 & 0.556 \\
1975 & 0.322 & 0.247 & 2.461 & 0.631 \\
1976 & 0.321 & 0.147 & 0.822 & 0.617 \\
1977 & 0.261 & 0.199 & 0.639 & 0.623 \\
1978 & 0.388 & 0.210 & 1.116 & 0.623 \\
1979 & 0.457 & 0.181 & 1.005 & 0.630 \\
1980 & 0.515 & 0.195 & 1.620 & 0.597 \\
1981 & 0.524 & 0.395 & 2.107 & 0.594 \\
1982 & 0.456 & 0.368 & 1.034 & 0.588 \\
1983 & 0.479 & 0.350 & 0.386 & 0.567 \\
1984 & 0.545 & 0.252 & 1.167 & 0.556 \\
1985 & 0.433 & 0.283 & 0.769 & 0.540 \\
1986 & 0.416 & 0.334 & 0.973 & 0.537 \\
1987 & 0.273 & 0.373 & 1.019 & 0.532 \\
1988 & 0.403 & 0.355 & 1.190 & 0.519 \\
\hline
\end{tabular}

Notes: See the text for the computation of the indexes.

Source: Statistics Denmark and authors calculations.

For the three measures above, we only have annual averages. The series are given in Table 3.

In the assessment of the importance of the observed indices we add the indices to the smooth transition model one by one. Therefore, the statistical model is reformulated as

$\Delta y_{t}=\Gamma_{0} \Delta \ln v_{t}+\Gamma_{1} \Delta x_{t-1}+\Gamma_{2} \Delta w_{t-1}+\alpha \delta+\alpha \beta^{\prime} x_{t-1}+\alpha \zeta^{\prime} w_{t-1}+\alpha \psi^{\prime} F(t)+\Phi D_{t}+\eta_{t}$,

where $w_{t}$ represents either one of the four shift variables and the model has been simplified relative to model (9) to reflect that we only include a single shift function. This means that $\psi$ is now a $2 \times 1$ vector instead of a $2 \times 2$ matrix. The new parameters $\Gamma_{2}$ and $\zeta$ are both $2 \times 1$ vectors.

To include the mismatch and turbulence measures in the model we compute quarterly observations by interpolation where it is assumed that within each year the series follow first order autoregressive processes with an autoregressive parameter of 0.9. ${ }^{16}$ Because of the interpolation we do not comment on the impact of the changes in the mismatch and turbulence measures $\left(\Gamma_{2}\right)$, we concentrate on the long run results $(\zeta)$.

When the two mismatch measures are included in the model, we expect parameters with opposite signs in the hiring function and the uv-curve as explained in Section III. Increased mismatch decreases the number of hirings for given levels of unemployment and vacancies $\left(\zeta_{1}<0\right)$, while unemployment is higher for a given vacancy rate $\left(\zeta_{2}>0\right)$. The same signs are expected when the replacement ratio enters the model. For the turbulence index we expect $\zeta_{1}=0$, as it should have no effect on the hiring function, while $\zeta_{2}>0$ because the reallocation shifts the uv-curve outwards as explained in section III.

\footnotetext{
${ }^{16}$ In the interpolation we used a standard procedure in RATS named distrib. src.
} 


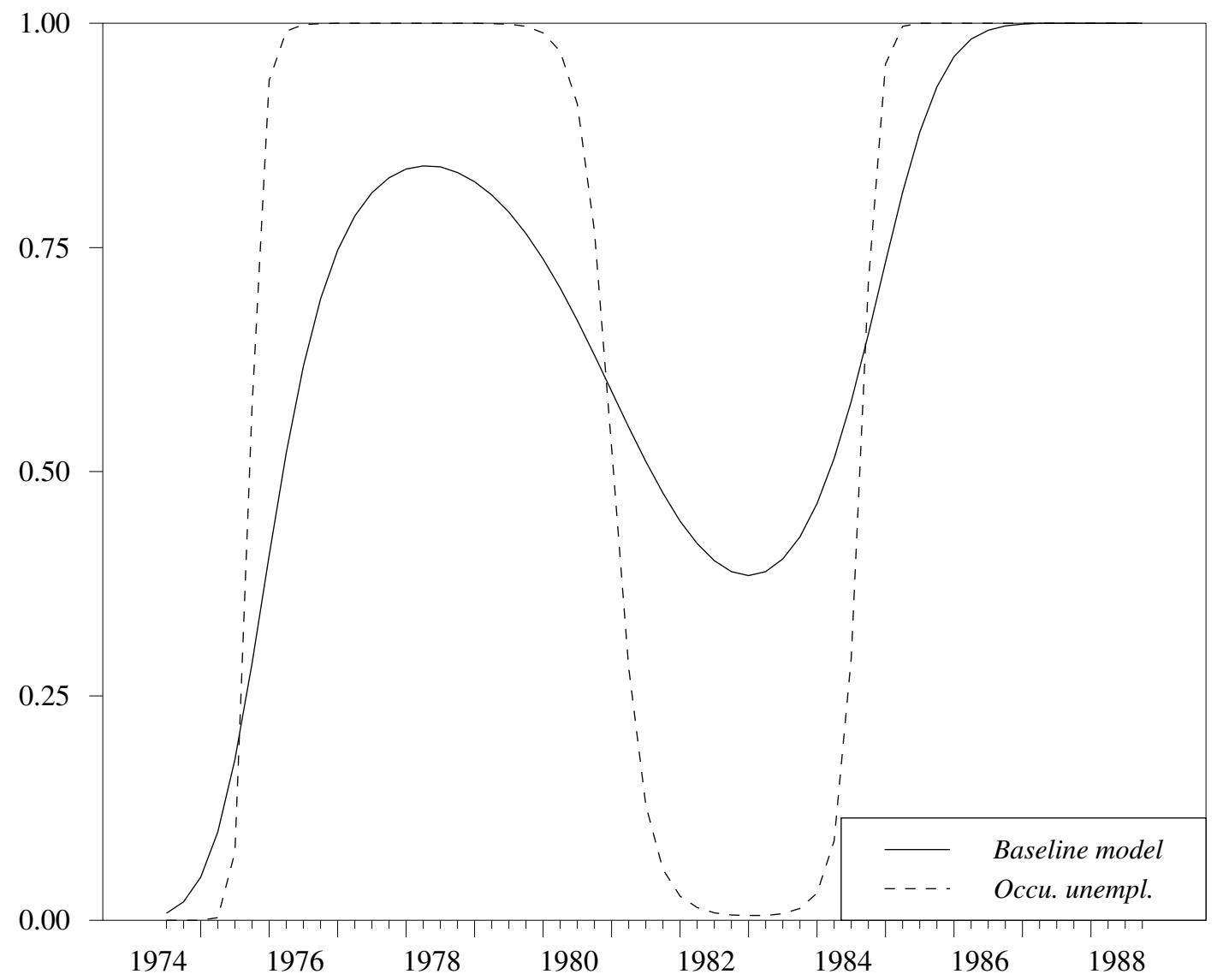

Figure 3. The smooth transition function in models with and without occupational unemplyment mismatch

Table 4 reports the results of including the two mismatch measures, the replacement ratio and the turbulence index. The parameters of the base-line model are given in the first two columns of Table 4 (Regression (1)) for reference.

Regression (2) adds the regional uv-mismatch variable to the model. As can be seen, there is virtually no change in the estimated parameters compared to the base-line model and the impact of regional uv-mismatch is highly insignificant both when tested individually in the hiring function and the uv-curve and jointly in a Wald test. Hence, we find no support for any level impact of changes in regional mismatch.

The results are somewhat different for mismatch based on the variation in occupational unemployment shown in Regression (3). This measure enters both relations with the expected signs and the impact on the hiring function is highly significant while the impact on the uv-curve is more uncertain. However, the smooth transition function is still highly significant when occupational unemployment mismatch is included and the parameters of the hiring function and the uv- curve are largely unchanged. One important change is in the parameters of the smooth transition function, which results in transitions with a much sharper profile compared to the transitions in the base-line model, see Figure 3. Thus, occupational unemployment mismatch appears to be important for the hiring function, but it does not capture the bulk of the changes in the two functions that is caused by changes in mismatch. 
TABLE 4

Regression results: Including observed mismatch and turbulence measures

\begin{tabular}{|c|c|c|c|c|c|c|c|c|c|c|}
\hline \multirow[t]{2}{*}{ Regression } & \multicolumn{2}{|c|}{$\begin{array}{c}(1) \\
\text { base model }\end{array}$} & \multicolumn{2}{|c|}{$\begin{array}{c}\text { (2) } \\
\text { uv-regional }\end{array}$} & \multicolumn{2}{|c|}{$\begin{array}{c}\text { (3) } \\
\text { u-occupational }\end{array}$} & \multicolumn{2}{|c|}{$\begin{array}{c}(4) \\
\text { replacement ratio }\end{array}$} & \multicolumn{2}{|c|}{$\begin{array}{c}\text { (5) } \\
\text { industry turbulence }\end{array}$} \\
\hline & $\ln h_{t}$ & $\ln u_{t}$ & $\ln h_{t}$ & $\ln u_{t}$ & $\ln h_{t}$ & $\ln u_{t}$ & $\ln h_{t}$ & $\ln u_{t}$ & $\ln h_{t}$ & $\ln u_{t}$ \\
\hline $\ln u_{t}$ & $\begin{array}{l}0.657 \\
(0.048)\end{array}$ & & $\begin{array}{l}0.651 \\
(0.056)\end{array}$ & & $\begin{array}{l}0.638 \\
(0.025)\end{array}$ & & $\begin{array}{l}0.536 \\
(0.037)\end{array}$ & & $\begin{array}{l}0.605 \\
(0.028)\end{array}$ & \\
\hline $\ln v_{t}$ & $\begin{array}{l}0.343 \\
(0.048)\end{array}$ & $\begin{array}{l}-0.265 \\
(0.048)\end{array}$ & $\begin{array}{l}0.349 \\
(0.056)\end{array}$ & $\begin{array}{l}-0.254 \\
(0.050)\end{array}$ & $\begin{array}{l}0.362 \\
(0.025)\end{array}$ & $\begin{array}{l}-0.303 \\
(0.032)\end{array}$ & $\begin{array}{l}0.464 \\
(0.037)\end{array}$ & $\begin{array}{l}-0.372 \\
(0.038)\end{array}$ & $\begin{array}{l}0.395 \\
(0.028)\end{array}$ & $\begin{array}{l}-0.302 \\
(0.032)\end{array}$ \\
\hline constant & $\begin{array}{l}1.708 \\
(0.188)\end{array}$ & $\begin{array}{l}-4.647 \\
(0.318)\end{array}$ & $\begin{array}{l}1.734 \\
(0.213)\end{array}$ & $\begin{array}{l}-4.591 \\
(0.342)\end{array}$ & $\begin{array}{l}1.972 \\
(0.128)\end{array}$ & $\begin{array}{l}-4.937 \\
(0.259)\end{array}$ & $\begin{array}{l}1.929 \\
(0.216)\end{array}$ & $\begin{array}{l}-5.192 \\
(0.312)\end{array}$ & $\begin{array}{l}2.038 \\
(0.153)\end{array}$ & $\begin{array}{l}-4.886 \\
(0.272)\end{array}$ \\
\hline$\hat{F}(t)$ & $\begin{array}{l}-0.599 \\
(0.144)\end{array}$ & $\begin{array}{l}0.486 \\
(0.109)\end{array}$ & $\begin{array}{l}-0.623 \\
(0.183)\end{array}$ & $\begin{array}{l}0.466 \\
(0.126)\end{array}$ & $\begin{array}{l}-0.408 \\
(0.050)\end{array}$ & $\begin{array}{l}0.327 \\
(0.063)\end{array}$ & $\begin{array}{l}-0.682 \\
(0.113)\end{array}$ & $\begin{array}{l}0.530 \\
(0.101)\end{array}$ & $\begin{array}{l}-0.579 \\
(0.071)\end{array}$ & $\begin{array}{l}0.435 \\
(0.074)\end{array}$ \\
\hline Shift variable & & & $\begin{array}{l}0.039 \\
(0.304)\end{array}$ & $\begin{array}{l}0.116 \\
(0.238)\end{array}$ & $\begin{array}{l}-1.065 \\
(0.213)\end{array}$ & $\begin{array}{l}0.386 \\
(0.207)\end{array}$ & $\begin{array}{l}0.874 \\
(0.335)\end{array}$ & $\begin{array}{l}-0.554 \\
(0.285)\end{array}$ & $\begin{array}{l}-0.095 \\
(0.029)\end{array}$ & $\begin{array}{l}0.023 \\
(0.028)\end{array}$ \\
\hline Wald test of shift variable & & & $\begin{array}{r}0 . \\
{[0 .}\end{array}$ & & $\begin{array}{l}26 \\
{[0} \\
\end{array}$ & & & & & $\begin{array}{c}11.04 \\
{[0.00]} \\
\end{array}$ \\
\hline \multicolumn{11}{|c|}{ Parameters of the transition function } \\
\hline$\gamma_{3}$ & $\begin{array}{l}-0 . \\
(0 .\end{array}$ & & $\begin{array}{l}-0 . \\
(0.3\end{array}$ & $\begin{array}{l}95 \\
14)\end{array}$ & $\begin{array}{l}-3 . \\
(1 .\end{array}$ & $\begin{array}{l}83 \\
41)\end{array}$ & $\begin{array}{l}-1 . \\
(0 .\end{array}$ & & & $\begin{array}{c}-0.899 \\
(0.281)\end{array}$ \\
\hline$\gamma_{2}$ & $\begin{array}{l}-7 . \\
(0 .\end{array}$ & & $\begin{array}{l}-7 . \\
(0.2\end{array}$ & $\begin{array}{l}60 \\
03)\end{array}$ & $\begin{array}{l}-7 . \\
(0 .\end{array}$ & $\begin{array}{l}51 \\
74)\end{array}$ & $\begin{array}{l}-7 . \\
(0.1\end{array}$ & & & $\begin{array}{c}-7.502 \\
(0.118)\end{array}$ \\
\hline$\gamma_{1}$ & $\begin{array}{l}17 \\
(1 .\end{array}$ & & $\begin{array}{l}16 . \\
(1.3\end{array}$ & $\begin{array}{l}384 \\
35)\end{array}$ & $\begin{array}{l}15 \\
(0 .\end{array}$ & $\begin{array}{l}293 \\
68)\end{array}$ & $\begin{array}{l}15 . \\
(0 .\end{array}$ & $\begin{array}{l}324 \\
78)\end{array}$ & & $\begin{array}{l}15.861 \\
(0.675)\end{array}$ \\
\hline$\gamma_{0}$ & $\begin{array}{l}-9 \\
(1 .\end{array}$ & & $\begin{array}{l}-8 . \\
(1 .\end{array}$ & $\begin{array}{l}50 \\
22)\end{array}$ & $\begin{array}{l}-6 . \\
(0 .\end{array}$ & $\begin{array}{l}26 \\
80)\end{array}$ & $\begin{array}{l}-6 . \\
(0.5\end{array}$ & $\begin{array}{l}33 \\
76)\end{array}$ & & $\begin{array}{l}-8.309 \\
(0.856)\end{array}$ \\
\hline
\end{tabular}

Notes: Conditional standard errors in parentheses. $p$-value of test statistic in brackets. 
Regression (4) shows that the level of the replacement ratio enters significantly in both the hiring function and the uv-curve, but with the wrong signs compared to what one would expect. Again there are only small changes in the other parameters in the system, therefore we conclude that the level of the replacement ratio is not a good candidate for explaining the increased mismatch.

Finally, the results for the turbulence index in Regression (5) show that the turbulence index has a significant, negative impact in the hiring function, while it is highly insignificant in the uv-curve. One interpretation of this result is that aggregate shocks create both more turbulence and more mismatch. ${ }^{17}$ Again, the constancy of the slope parameters of the hiring function and the uv-curve are striking.

Summing up, we find that observed measures of mismatch and turbulence do impact on hires at given unemployment and vacancy rates. But the impact on the uv-curve is more uncertain. Moreover, none of the measures are capable of describing the changes in the levels found using the smooth transition function.

\section{Conclusion}

In this paper we have developed a framework for testing the two main hypotheses for the outward shift in the uv-curve, which has been a common phenomena in many countries. One hypothesis is increased reallocation in the labour market: a higher level of separations at a given level of employment. The other hypothesis is increased mismatch in the labour market: a lower level of hires, given unemployment and vacancies. The basis for the test is the observation that increased mismatch will shift the hiring function downwards, while this is not the case when reallocation increases.

The outcome of the test in the case of the rise in Danish unemployment is that the shift in the uv-curve and the hiring function have been analogous, such that the mismatch hypothesis is accepted. This is in contrast to the conclusion for the US by for example Blanchard and Diamond (1990), who attribute at least a part of the outward shift in the uv-curve to increased reallocation.

The devices used in this paper to describe the shifts in the uv-curve and the hiring function are smooth transition functions, which are bounded between zero and one. When these functions are included in the equations for the curves, the coefficients of the transition functions have the attractive property that they measure the proportional shifts of the curves. Furthermore, as the functions are bounded, they do not imply that a drift in the uv-curve continues indefinitely after the sample period, which is the case when a linear trend is included in the equation.

Finally, the inclusion of a transition function in estimations with and without indices makes it possible to assess the share of the outward shift in the uv-curve that can be attributed to the indices. Using this idea we find that occupational mismatch, given as the variance in unemployment rates across unemployment insurance funds, made significant contributions to the increase in Danish unemployment during the late 1970s and the 1980s. But occupational mismatch is only part of the mismatch problem.

The inclusion of the transition functions applied in this paper seems to be valuable even when including indices for either reallocation or mismatch in the equation for a

\footnotetext{
${ }^{17}$ See Abraham and Katz (1986) and Jackman, Layard and Savouri (1990).
} 
uv-curve is attempted. Such indices have not been able to describe the whole outward shift in the curves, which implies that the inclusion of a transition function will provide a convenient assessment of the magnitude of the remaining proportional shift.

\section{References}

Albæk, K. and Sørensen, B. (1998). 'Worker flows and job flows in Danish manufacturing, 198091', Economic Journal, Vol. 108, pp. 1750-1771.

Abraham, K. (1987). 'Help-wanted advertising, job vacancies, and unemployment', Brookings Papers on Economic Activity, Vol. 1, pp. 207-248.

Abraham, K. and Katz, F.L. (1986). 'Cyclical unemployment: sectoral shifts or aggregate disturbances?', Journal of Political Economy, Vol. 94, pp. 507-522.

Anderson, P.M. and Burgess, S. M. (2000). 'Empirical matching functions: estimation and interpretation using state-level data', Review of Economics and Statistics, Vol. 82, pp. 93-102.

Bingley, P., Eriksson, T., Werwatz, A. and Westergård-Nielsen, N. (1999). 'Beyond 'Manucentrism' - Some Fresh Facts About Job and Worker Flows', CLS Working paper, 99-09, University of Aarhus and Aarhus School of Business.

Blanchard, O. J. and Diamond, P. A. (1990). 'The aggregate matching function', in P. A. Diamond, ed., 'Growth/Productivity/Unemployment', Cambridge: MIT Press, pp. 159-201.

Broersma, L. and Van Ours, J.C. (1999). 'Job searchers, job matches and the elasticity of matching', Labour Economics, Vol. 6, pp. 77-93.

Burda, M. and Wyplosz, C. (1994). 'Gross worker and job flows in Europe', European Economic Review, Vol. 38, pp. 1287-1315.

Budd, A., Levine, P. and Smith, P. (1988). 'Unemployment, vacancies and the long-term unemployed', Economic Journal, Vol. 98, pp. 1071-1091.

Burgess, S. M. (1993). 'A model of competition between unemployed and employed job searchers: an application to the unemployment outflow rate in Britain', Economic Journal, Vol. 103, pp. 1190-1204.

Davis, S. and Haltiwanger, J. (1992). 'Gross job creation, gross job destruction, and employment reallocation', Quarterly Journal of Economics, Vol. 107, pp. 819-863.

Davis, S. and Haltiwanger, J. (1999). 'Gross job flows', in O. Ashenfelter and D. Card, eds., Handbook of Labor Economics, Vol. 3B, ch. 41, Amsterdam: Elsevier, pp. 2711-2805.

Franz, W. (1987). 'The end of expansion in employment in Germany', in P. J. Pedersen and R. Lund, eds., Unemployment: Theory, Policy and Structure, Berlin: deGruyter, pp. 81-103.

Hansen, H. and Johansen, S. (1999). 'Some tests for parameter constancy in cointegrated VARmodels', Econometrics Journal, Vol. 2, pp. 306-333.

Harboe, I., Johansen, S., Nielsen, B. and Rahbek, A. (1998). 'Asymptotic inference on cointegration rank in partial systems', Journal of Business and Economics Statistics, Vol. 16, pp. 388-399.

Jackman, R., Layard, R. and Pissarides, C. (1989). ‘On vacancies', Oxford Bulletin of Economics and Statistics, Vol. 51, pp. 377-394. 
Jackman, R., Layard, R. and Savouri, S. (1990). 'Mismatch: a framework for thought', in F. P. Schioppa (ed.) Mismatch and Labour Mobility, Cambridge: Cambridge University Press for CEPR, pp. 44-101.

Jackman, R., Pissarides, C. and Savouri, S. (1990). 'Labour market policies and unemployment in the OECD', Economic Policy, Vol. 5, pp. 449-490.

Johansen, S. (1996). Likelihood-based inference in cointegrated vector autoregressive systems, 2nd ed., Oxford: Oxford University Press.

Layard, R., Nickell, S. and Jackman, R. (1991). Unemployment. Macroeconomic Performance and the Labour Market, Oxford: Oxford University Press.

Lilien, D. M. (1982). 'Sectoral shifts and cyclical unemployment', Journal of Political Economy, Vol. 90, pp. 777-793.

Lin, C.-F. J. and Teräsvirta, T. (1994). 'Testing the constancy of regression parameters against continous change', Journal of Econometrics, Vol. 62, pp. 211-228.

Mumford, K. and Smith, P.N. (1999). 'The hiring function reconsidered: on closing the circle', Oxford Bulletin of Economics and Statistics, Vol. 61, pp. 343-364.

Pissarides, C. A. (1985). 'Short-run equilibrium dynamics of unemployment, vacancies, and real wages', American Economic Review, Vol. 75, pp. 676-690.

Pissarides, C. A. (1986). 'Unemployment and vacancies in Britain', Economic Policy, Vol. 3, pp. $499-559$.

Pissarides, C. A. and Petrongolo, B. (2001). 'Looking into the black box: a survey of the matching function', Journal of Economic Literature, Vol. 39, pp. 390-431.

Robson, M.T. (2001). 'Regional variations in the competitiveness of unemployed job-seekers and the rate of outflows from unemployment', Oxford Bulletin of Economics and Statistics, Vol. 63, pp. 61-90.

Sløk, T. (1997). 'Er der mismatch-problemer på det danske arbejdsmarked?', Samfunds $\emptyset$ konomen, Vol. 8, pp. 13-17.

Wall, H.J. and Zoega, G. (2002). 'The British Beveridge curve: a tale of ten regions', Oxford Bulletin of Economics and Statistics, Vol. 64, pp. 257-267. 